\title{
EL FEMINISMO DE LA SEGUNDA OLA EN MÉXICO Y SU RELACIÓN CON OTROS MOVIMIENTOS DE MUJERES \\ Yearim A. Ortiz San Juan*
}

RESUMEN: Las neofeministas, al articular las esferas privada y pública, evidenciaron la violencia sexual que se ejercía sobre las mujeres. Para estudiar este movimiento, conviene hacer una breve historia de la segunda ola del feminismo en México, particularmente el de Ciudad de México, y explicar cómo sus postulados pasaron a formar parte de la agenda política.

PALABRAS CLAVE: neofeminismo, esfera privada y esfera pública.
THE FEMINISM OF THE SECOND WAVE IN MEXICO AND ITS RELATIONSHIP WITH OTHER WOMEN'S MOVEMENTS

ABSTRACT: The neo-feminist women, when articulating the private and public spheres, evidenced the sexual violence that was exercised on women. In order to study this movement, it is convenient to make a brief history of the second wave of feminism in Mexico, particularly that of Mexico City, and to explain how its postulates became part of the political agenda.

KEYWORDS: neofeminism, private sphere and public sphere.

* Investigadora asociada del Centro de Estudios en Derechos Humanos, A.C.
ACEPTACIÓN: 14 de septiembre de 2018. DoI: $10.5347 / 01856383.0131 .000296733$ 


\section{EL FEMINISMO DE LA SEGUNDA OLA EN MÉXICO Y SU RELACIÓN CON OTROS MOVIMIENTOS DE MUJERES*}

Fue una revelación que me llevó a una rebelión [...] y nada queda como antes para el resto de tu vida.

Marta Acevedo**

\section{Si hablar de los movimientos sociales} del México del siglo XX resulta complicado, tampoco es sencillo estudiar en concreto el feminismo y sus múltiples caras. En este artículo se explica cómo se desarrolló el movimiento feminista mexicano desde la década de 1970 hasta finales del siglo XX. Son dos los objetivos: primero, analizar el proceso por el cual lo privado se volvió público y dio como resultado la visibilización de la violencia sexual ejercida sobre la mujer; y segundo, comprender cómo el feminismo pasó de ser una herramienta de búsqueda personal a ser un movimiento político, es decir, cómo se logró institucionalizar $\mathrm{y}$ formar parte de la vida política. ${ }^{1}$

*El presente artículo es parte de la tesis de maestría en historia titulada "La victimización de las mujeres en la ciudad de México. El transporte público como espacio de su visibilización", en la que, desde la categoría de victimización, analizo la política pública "Viajemos seguras" para entender cómo, sin quererlo, se ha reforzado la figura del hombre como un agresor y la de la mujer como el de un ser indefenso.

** Marta Acevedo, "Lo volvería a elegir", Debate feminista, 12 (1995), pp. 3-21.

${ }^{1}$ Vale la pena remarcar que el trabajo se centra solamente en el movimiento feminista de la Ciudad de México. Las capitalinas vivieron el movimiento del 68 de una manera distinta que en los estados de la república. Así, tenemos versiones como la de Amalia García, nacida en Zacatecas, quien sostiene que los ecos del movimiento estudiantil la impulsaron al activismo político, en el que conoció y asumió el feminismo. A diferencia de las relaciones que tuvieron las capitalinas con las feministas estadounidenses, la diputada del PRD sostuvo amplia correspondencia con las feministas comunistas italianas (aunque hay que decir que también participó de la fiebre feminista de Ciudad de México mientras estudiaba en la UNAM; entrevista de la autora con Amalia García, Ciudad de México, 17 de octubre de 2012). Por consiguiente, no podemos asumir que el feminismo capitalino es igual que el de los estados, tanto por la influencia de otras corrientes feministas internacionales, como por su participación en las instituciones. 
El artículo se divide en dos apartados. En el primero se analiza el movimiento de la segunda ola feminista a partir de la década de 1970 y se explican sus condiciones de posibilidad. Se aclara cómo el legado de la primera ola les permitió a las hijas del sufragio articular las esferas pública y privada, hasta ese momento separadas, y cómo, a partir de esa misma articulación, la violencia hacia la mujer comenzó a tomar relevancia en el campo político.

En el segundo apartado se aborda la fragmentación del movimiento feminista y lo que lo unió a otros movimientos de mujeres. Se observará cómo se empezó a institucionalizar el feminismo para dar empuje a una agenda política específica y cómo el proceso fue cambiando el paradigma de la violencia sexual.

Es pertinente hacer algunas aclaraciones preliminares para comprender plenamente el proceso feminista. En un plano discursivo, el movimiento se puede dividir en dos: el de la igual$\mathrm{dad}$, que suele ser relacionado con la primera ola, el feminismo que posibilitó el ingreso de las mujeres al ámbito de lo público con el sufragio y cuyo problema, según las feministas de la segunda ola, fue que se articuló según un código patriarcal. El segundo, el de la diferencia, logró trascender la condición femenina para explicarse en términos de género. Su postura se puede resumir bajo la máxima "lo personal es político". ${ }^{2}$

En el plano de la praxis social, Eli Bartra ${ }^{3}$ y muchos otros autores utilizan el término neofeminismo para referirse al movimiento de la segunda ola, aquel que vino después del movimiento sufragista y que va más allá de una lucha por la igualdad de derechos políticos y sociales. Lo que caracteriza al neofeminismo es su lucha por la conquista de la libertad sobre el propio cuerpo, es decir, una lucha por la soberanía del cuerpo femenino frente al sometimiento del varón. Gilles Lipovetsky ${ }^{4}$ advierte que el neofeminismo es el movimiento que busca una regulación pública de todas las conductas privadas, incluyendo la sexualidad. Así, las neofeministas se apegan a la máxima "lo personal es político", poniendo el acento en

${ }^{2}$ Resulta difícil etiquetar de esa forma al feminismo. En realidad, deberíamos hablar de feminismos, pues en el discurso se puede observar toda una gama de feminismos. Hay quien prefiere hablar del feminismo liberal, en lugar del de igualdad, y quien al hablar del feminismo de la diferencia se sustenta en términos ontológicos de la distinción entre hombres y mujeres. Tomo la distinción de la socióloga y académica del Colmex María Luisa Tarrés, "Discurso y acción política feminista", en Marta Lamas (coord.), Miradas feministas sobre las mexicanas del siglo XX, 2007, México, FCE/Conaculta, pp. 113-148.

${ }^{3}$ Eli Bartra, "Tres décadas de neofeminismo en México", en Eli Bartra, Anna M. Fernández Poncela y Ana Lau, Feminismo en México, ayer y hoy, 2002, México, UAM, pp. 45-81.

${ }^{4}$ Gilles Lipovetsky, La tercera mujer. Permanencia y revolución de lo femenino, 2007, Barcelona, Anagrama. 
aquello que por excelencia y por años estuvo fuera de toda regulación estatal: el sexo y el placer. Para Elena Urrutia, ${ }^{5}$ el neofeminismo comenzó a cuestionar la naturalidad de la opresión de la mujer y el orden social que reproducía esa condición: el patriarcado. Vemos que, en general, el término se utiliza para hablar de aquel feminismo que se contrapone al de corte liberal o de la igualdad. Es decir, se usa para distinguirlo del feminismo que pugna por la igualdad entre hombres y mujeres y que, aunque ataca y evidencia la discriminación sexual, no rompe con la lógica de las esferas privada y pública.

\section{Las condiciones de posibilidad para un nuevo feminismo}

Las décadas de 1960 y 1970 estuvieron marcadas por movimientos sociales y culturales producidos por el malestar social y también, de forma particular, por la transformación de los valores asociados a la autoridad, la familia y la libertad sexual entre las generaciones jóvenes. ${ }^{6}$

${ }^{5}$ Elena Urrutia (coord.), Estudios sobre las mujeres y las relaciones de género en México: Aportes desde diversas disciplinas, 2002, México, Colmex-PIEM.

${ }^{6}$ Véase María de la Paz López, "Las mujeres en el umbral del siglo XX”, en Marta Lamas (coord.), op. cit., pp. 79-112.
El movimiento de la primera ola feminista ya había abonado el terreno para que los jóvenes cuestionaran a sus padres y a un Estado autoritario que se encontraba en un franco desgaste. Ya en la década de 1950 las mujeres habían alcanzado el sufragio y poco a poco se habían abierto paso en la esfera pública. El voto solo había sido la cereza del pastel, pues la mujer había conquistado un espacio que le había sido vedado por años: además de elegir a sus gobernantes, también estudiaba y trabajaba junto a sus compañeros. Esto ayuda a comprender los cambios que se produjeron en la institución de la familia, que permitieron pensar lo privado desde otra perspectiva y cuestionar la relación entre la esfera privada y la pública, así como los papeles que por tradición habían sido asignados a los géneros. ${ }^{7}$

A mediados de la década de 1960 se respiraba un descontento en la clase media, sobre todo respecto al autoritarismo político que buscaba la centralización del poder como condición para la estabilidad del país. Recordemos que el triunfo de la revolución cubana y la rivalidad entre Estados Unidos y la URSS trajo una fiebre de ideas que ponían en entredicho la

${ }^{7}$ La creciente y sostenida incorporación de las mujeres al sistema de educación formal y al mercado laboral impactó en la vida cotidiana y en la percepción de los papeles de hombres y mujeres. Esto trajo como resultado que los espacios público y privado comenzaran a trastocarse, pues al salir muchas mujeres a trabajar la ecuación en la casa se dislocó. 
legitimidad del partido hegemónico como el heredero de la Revolución Mexicana. Sumado a esto, la Iglesia católica marcó su propio camino llevando su mirada hacia las clases menos favorecidas como resultado del Concilio Vaticano II.

Toda esta irrupción de ideologías y cuestionamientos trajo consigo una triple crisis en la noción de la autoridad y su praxis: por un lado, las nuevas generaciones cuestionaban no solo la represión del Estado, sino su propia legitimidad, basada en un partido único que se fundaba en los supuestos valores de la Revolución. Así, buscaban la participación en los espacios públicos como un ejercicio democrático y libre. Fue el movimiento estudiantil del 68 el que puso de manifiesto, de manera contundente, el descontento social hacia las políticas autoritarias. Igualmente se disputaba la estructura vertical del orden familiar, en donde el padre - haciendo referencia a la imagen del Estado hegemónico - ostentaba toda autoridad sobre los demás miembros. La irrupción de los jóvenes - sobre todo las mujeres - en el espacio público, la aparición de la píldora anticonceptiva y la revolución sexual desestabilizaron el dominio omnipresente del padre sobre los hijos y, quizá, sobre la esposa. Finalmente, la Iglesia católica de América Latina se alejó del poder unívoco y vertical de la Iglesia institucional. Se acrecentó la participación de los laicos organizados en movimientos sociales, y la ideología asociada a la izquierda se apoderó de un gran sector de esa institución ${ }^{8}$ y enfocó sus esfuerzos en la promoción del desarrollo personal y social, sobre todo en las zonas rurales. Se puso en crisis la moral sexual católica, que coincidía con la moral tradicional de la familia revolucionaria. ${ }^{9}$

Estas crisis fomentaron la participación activa de la sociedad. Muchos núcleos sociales se organizaron en movimientos específicos que hicieron frente a la asfixia del poder

${ }^{8}$ María Luisa Aspe Armella, refiriéndose a la Conferencia General del Episcopado Latinoamericano en Medellín, en 1968, concluyó que "empezaron a cultivarse ideas que asemejaban más a Jesús con el Che Guevara que con la jerarquía vaticana". María Luisa Aspe Armella, guion para el programa "Estado, empresarios e Iglesia en la década de los 60" del Canal 22.

${ }^{9}$ El desarrollo de las relaciones de noviazgo entre las parejas jóvenes - centrada sobre todo en la moral sexual - y la moral que debía regir la institución de la familia no fue solo motivo de preocupación para la Iglesia, sino también para el Estado, que cimentó el modelo de la "familia revolucionaria" en los valores de la clase media, valores que se fincaban en la religión católica. Esto se tradujo en campañas de moralización que se vieron reflejadas en la prensa y en el cine, por ejemplo. Al respecto, recomiendo el artículo de Valentina Torres Septién, "Bendita sea tu pureza: relaciones amorosas de los jóvenes católicos en México (1940-1960)", en Tradiciones y conflictos. Historias de la vida cotidiana en México e Hispanoamérica, 2007, México, Colmex, pp. 385-413; y Eric Zolov, Rebeldes con causa. La contracultura mexicana y la crisis del Estado patriarcal, 2002, México, Norma. 
autoritario. Así pues, los recelos hacia las acciones gubernamentales "dejaron el campo abierto a la acción de las organizaciones sociales y civiles". ${ }^{10}$ Los católicos formaron comunidades cristianas de base que buscaron estar a tono con las nuevas demandas de los sectores populares. El sindicalismo independiente se reforzó, los estudiantes levantaron la voz y exigieron que se respetara la autonomía de su alma mater, los obreros reclamaron mejores condiciones de trabajo y las mujeres comenzaron también a movilizarse.

Surgieron movimientos que lucharon, por un lado, por renovar la relación entre los ciudadanos y el Estado, y por el otro, por cambiar el paradigma institucional de la familia. En este punto cobró importancia el movimiento feminista, que al replantear la condición social de las mujeres, cuestionó las pautas instituidas que normaban las relaciones familiares, que solo pudieron ser pensadas a partir de los movimientos estudiantiles y con la inserción de la mujer en la esfera pública.

\footnotetext{
${ }^{10}$ Gustavo Verduzco Igartúa, "Las organizaciones solidarias en México”, en Ilán Biezberg y Lorenzo Meyer (coords.), Una historia contemporánea de México: Actores, 2005, México, Océano, p. 371.
}

El mujerismo. ${ }^{11}$ Los grupos de autoconciencia como la base de la nueva ola

Tenemos entonces que el sexo femenino irrumpió con el voto en el espacio público y por un glorioso momento sintió que la igualdad entre hombres y mujeres había sido alcanzada. ${ }^{12} \mathrm{Sin}$

${ }^{11}$ El término "mujerismo" es utilizado por la antropóloga Marta Lamas en su artículo "De la protesta a la propuesta: El feminismo en México a finales del siglo XX", en Isabel Morant, et al., Historia de las mujeres en España y América Latina, 2006, Madrid, Cátedra, pp. 903-921. Lamas divide el movimiento feminista de la segunda ola en dos momentos: el primero, el mujerismo, se distinguió por una utopía revolucionaria que mistificaba las relaciones entre hombres y mujeres, y por una política arraigada en la identidad; esto se debió a que el movimiento se concentró en los grupos de autoconciencia en los que la mayoría de las mujeres (que eran de clase media) vivían el feminismo como un instrumento de análisis o de búsqueda personal. El segundo, la institucionalización, se caracterizó por la lenta relevancia de los grupos de autoconciencia en la vida política, quedando atrás la utopía revolucionaria y revalorizando el papel de la democracia. $\mathrm{Al}$ dar un giro en este aspecto, les resultó obvia, a las feministas, la necesidad de integrarse a la dinámica política del país. Así, muchas se subieron al tren democrático y se afiliaron a los partidos políticos. El caso más relevante es el del Partido de la Revolución Democrática.

${ }^{12}$ Es necesario recalcar que la primera ola feminista buscaba la igualdad, no la equidad. Suponían que alcanzando la igualdad ciudadana las mujeres podrían estar a la par de sus compañeros. En cambio, la nueva ola, la neofeminista, reparó en la diferencia y concluyó que es la que ocasiona la sumisión. En opinión del neofeminismo, se requieren leyes y formatos especiales, pues todos los códigos sociales están estructurados en un lenguaje masculino, lo que impide la plena libertad de las mujeres. 
embargo, había algo que seguía causando incomodidad. Uno de los factores clave que puso en evidencia la molestia que subsistía bajo la supuesta igualdad, fue el movimiento del $68 .^{13}$ Las mujeres tuvieron una gran participación en el movimiento, pero no fue reconocida. Esta inadvertencia fue vivida por las capitalinas como un rechazo y un desprecio por parte de los dirigentes políticos. De tal manera, estas universitarias - de clase media - se dieron cuenta de que la igualdad jurídica en realidad era una reivindicación muy limitada: seguían sin tener el reconocimiento político. El 68 dejó una huella profunda en ellas, pues comenzaron a desconfiar de toda institución y de todo intento de politización.

Si bien el que las jóvenes de entonces pudieran salir del hogar, trabajar y estudiar, generó un cambio en el ideal de la mujer como ama de casa, su aparente libertad en la esfera pública era muy limitada. Seguían ocultas tras el discurso político como si no formaran parte de la esfera pública. Aunque participaban en los nuevos movimientos sociales, su intervención era vista solo como un apoyo solidario. $^{14}$

${ }^{13}$ Véase María Luisa Tarrés, "Discurso y acción política feminista”, en op. cit., pp. 113-148.

${ }^{14} \mathrm{Al}$ respecto, véase Marta Acevedo, "Lo volvería a..." op. cit. El artículo es una entrevista de Marta Lamas a la feminista Marta Acevedo sobre su vida personal en relación con su militancia como
En la década de 1970 se formaron grupos de autoconciencia en los que las jóvenes universitarias analizaron y discutieron, a partir de su vida personal, su condición como mujeres en la vida cotidiana, sobre todo en el terreno sexual. Al ser grupos de autoconciencia, se constituyeron como un movimiento diferente al de sus compañeros, y desde ahí criticaron la doble moral sexual y el papel del ama de casa. Este nuevo feminismo advirtió que para poder tener acceso pleno a la esfera pública, primero se debía ser libre en la esfera privada; es decir, que para que las mujeres dejaran de ser vistas como un apoyo en el espacio público, tenían que conquistar la igualdad en el espacio privado. ${ }^{15}$ Hay que subrayar que esto fue posible no solo

feminista. Marta Acevedo es considera una de las primeras feministas de la segunda ola, pues fue de las fundadoras, junto con otras dos mujeres, de los grupos de autoconciencia. Aquí, la entrevistada narra su participación en diversos movimientos y su incomodidad al no ser incluida en las demandas específicas.

${ }^{15}$ Marta Lamas, "La antropología feminista y la categoría 'género"', en Marta Lamas (coord.), $E l$ género. La construcción cultural de la diferencia sexual, 2003, México, Pueg-UnAM, pp. 97-125. La autora explica cómo en la década de 1970 se analizó la relación entre el capitalismo y la dominación patriarcal, descartando la supuesta "naturalidad" de ciertos aspectos de la subordinación de las mujeres. Esta "naturalidad" se entiende en su ser madre, y por lo tanto, en el lugar especial que se le asigna en el cuidado de la casa. Su estancia en la esfera privada se debe, primordialmente, a su asimilación con lo natural, y al del hombre, en la esfera pública, con lo cultural. Así pues, podríamos decir que se inicia una "desnaturalización" de la esfera privada. 
por el cambio de paradigma y por los movimientos sociales que ponían en evidencia el resquebrajamiento del partido único, sino porque estas mujeres eran en su mayoría jóvenes de clase media y estudiantes. Así, al tener resuelto el trabajo de la casa y el cuidado de los hijos con empleadas domésticas, pudieron formar grupos en los que vivían el feminismo como un instrumento de análisis social o de búsqueda personal, sin la necesidad de organizarse institucionalmente para enfrentar la problemática que habían vislumbrado respecto a su participación en la esfera pública. ${ }^{16}$ Gracias a los grupos de autoconciencia, las relaciones cotidianas entre hombres y mujeres comenzaron a cuestionarse y las dos esferas, antes separadas, empezaron a perder poco a poco sus límites. ${ }^{17}$

Uno de los primeros resultados visibles de la crítica a la esfera privada fue la protesta que realizaron varias decenas de personas, convocadas por

${ }^{16}$ Lamas, "De la propuesta a la propuesta".

${ }^{17}$ Como afirma María Luisa Terrés: "La vida cotidiana se identifica entonces como el lugar donde las mujeres sufren las consecuencias del poder patriarcal y la lucha contra el autoritarismo permite articular dos esferas, la pública y la privada, hasta entonces separadas". "Apuntes para un debate sobre el género, la política y lo político", en Urrutia, op. cit., p. 293. Esta articulación se debe, en gran medida, a la teorización del concepto "género". Esta categoría ayuda a pensar los procesos de diferenciación, dominación y subordinación entre los hombres y las mujeres, remitiéndolos a la fuerza de lo social, lo que abre la posibilidad de transformar las costumbres e ideas. la agrupación Mujeres en Acción Solidaria (el primer grupo de autoconciencia) el 10 de mayo de 1971 frente al Monumento a la Madre, en la Ciudad de México, cuando censuraron el estereotipo materno que exaltaba el autosacrificio y la falta de autonomía individual como cualidades inherentes al ser madre.

Por otra parte, además de cuestionar los papeles de género y reflexionar en torno a la familia y sus valores, también polemizaron respecto a la sexualidad, la cual había sido encerrada, también, en la esfera privada. Todas estas reflexiones permitieron evidenciar la violencia que se ejercía sobre las mujeres:

Los grupos de autoconciencia criticaron la opresión sufrida por las mujeres debido al trabajo doméstico, al papel de esposa y ama de casa, pero sobre todo se preocuparon por la sexualidad y la violencia pues el peso del machismo y la doble moral sexual presentes en la cultura nacional producían una irritación e impotencia colectivas. ${ }^{18}$

Se debía eliminar todo tipo de violencia provocada por una cultura machista e ir más allá de la reivindicación jurídica que con tanto celo habían buscado las feministas de la primera ola. ${ }^{19}$

${ }^{18}$ Tarrés, op. cit., p. 127.

${ }^{19}$ Por ejemplo, en 1975 un grupo de mujeres formó el Frente contra el Año Internacional de la 
Así, se crearon discursos muy específicos y una red identitaria que mantuvo unidos, por algún tiempo, a los diversos grupos de autoconciencia feministas. Estas primeras activistas formaron relaciones entre ellas a partir de las siguientes demandas: la maternidad voluntaria - que implica el derecho a una buena educación sexual y el acceso legal al abortoel alto a la violencia sexual y el derecho a la libre opción sexual. ${ }^{20} \mathrm{Su}$ pensamiento queda perfectamente resumido con el lema "lo personal es político".

Tras el movimiento del 68 las nuevas feministas optaron por darle la espalda a las instituciones, que fueron vistas como traidoras, y emprendieron su activismo desde los grupos de autoconciencia. Sin embargo, como veremos adelante, algunas se dieron cuenta de que para conseguir sus demandas era necesario hacer pactos políticos con el Estado y con otras organizaciones civiles. En la década de 1970, el movimiento se dedicó más a impugnar las acciones del gobierno y los partidos, así como la cultura machista, que a dialogar. Esto resultó complicado para el mismo movimiento,

Mujer y llevaron a cabo un "contracongreso" que cuestionaba las reuniones de la Organización de las Naciones Unidas y criticaba la igualdad jurídica entre hombres y mujeres, advirtiendo que era una reivindicación muy limitada.

${ }^{20}$ Algunas autoras, como Gabriela Cano, agregan a las máximas la socialización del trabajo doméstico y dejan fuera la libre opción sexual. pues no logró traducir sus propuestas a un lenguaje comprensible para todos, y se fue ensimismando. Lo que distinguió al movimiento de esta época es que eran pocas y autónomas. La organización en pequeños grupos regados por la ciudad tenía como objetivo subrayar su carácter autónomo frente a todo partido político, sindicato y demás organizaciones. No obstante, hubo mujeres que practicaron la doble militancia, es decir, que formaron parte tanto del movimiento autónomo como de algún partido o sindicato, pese a que las críticas no se hicieron esperar. Su reacción era comprensible y justificable, pues quizá era la única forma en que podían hacerse notar en un espacio ocupado por el discurso masculino. ${ }^{21}$

A pesar de que en determinado momento pretendieron entablar un diálogo para plantear sus postulados -más allá de los meros grupos de autoconciencia-, su misma independencia les cerró las puertas, pues el hecho de ser un movimiento dirigido por unas cuantas fue cuestionado por

${ }^{21}$ María Luisa Tarrés afirma que parte del éxito como movimiento social se debió a la creciente deslegitimación del partido único y la debilidad de los partidos de oposición (por lo menos hasta 1988), pues de esta manera ellas tuvieron que organizarse fuera del ámbito institucional y desde ahí plantear sus ideas: "Ese ambiente político permitió crear espacios colectivos fuera de la lucha partidaria, donde las mujeres reflexionaron sobre su subordinación y la necesidad de individualizarse para constituirse como personas libres y útiles a su sociedad", op. cit., p. 114. 
otras mujeres como una expresión pequeñoburguesa, que no le interesaba la condición de las mujeres de otros ámbitos, como las indígenas o las pobres. Para inicios de la década de 1980, el diálogo entre las feministas y las propiamente no feministas (según las primeras) provocó el quiebre de los postulados de las neofeministas y las fragmentó. De un lado quedaron las que llevaron la individualidad a todos los campos y buscaron abarcar también al sector popular con sus demandas, y del otro las que se cerraron aún más al diálogo, alegando que los postulados de los movimientos de mujeres no tenían por qué ser abrazados por el movimiento feminista.

\section{8 \\ La violencia sexual como punto de unión del feminismo y los movimientos de mujeres}

Antes de entrar de lleno al proceso de institucionalización del movimiento feminista y de la articulación de sus demandas, es preciso analizar el discurso que le dio visibilidad y que a un tiempo lo unió con otros movimientos y lo fragmentó. Como vimos, las feministas comenzaron a moverse según la máxima "lo personal es político", que solo tiene lógica cuando lo individual prima sobre lo colectivo, es decir, cuando el yo se destaca frente a la sociedad. Al señalar la importancia de la diferencia, el movimiento abrió camino para la introducción del otro en lo político:

esta propuesta $[\ldots]$ habla sobre "un cambio general que es también un cambio en uno mismo" y por ello "produce una tensión dramática, fuente de la fuerza y la fragilidad del movimiento feminista que debe afirmar la diferencia y al mismo tiempo no renunciar a la racionalidad colectiva", esto es, a la integración de las mujeres a la sociedad y a las instituciones. ${ }^{22}$

Resultó que la "diferenciación" fue la base común para diversos grupos; pero al mismo tiempo, la base común se volvió lo no común. El discurso le dio una ventaja a su acción, pues definió una exclusión compartida, lo que unió a diversos sujetos también excluidos y creó una masa "uniforme" que hacía las mismas demandas políticas y otras diferentes. Es decir, de alguna forma se facilitó una identidad política: "Las mujeres logran entrar a la vida pública nacional e internacional gracias a que tejen una trama de grupos y organizaciones y al mismo tiempo crean una comunidad de discurso que les otorga identidad política". ${ }^{23}$ Se buscó, en última instancia, que el sistema institucional

${ }^{22}$ Ibid., p. 117.

${ }^{23}$ Ibid., p. 120. 
reparara el código que las excluía en razón de su sexo.

A pesar de que la máxima "lo personal es político" permitió la emergencia del neofeminismo, también impidió que avanzara significativamente en los primeros años. Con ese discurso se hizo visible la importancia de la diferencia (sello característico de la nueva ola). Sin embargo, al postular las feministas que su lucha era por la soberanía de sí mismas - lo personal - frente a los varones - lo político-, no admitieron la diferencia más allá de lo femenino y lo masculino. Aquí se produjo la fractura y los puntos, hoy en día, irreconciliables con las "feministasradicales-activistas". ${ }^{24}$

Como vimos, las diversas activistas formadas en los grupos de autoconciencia centraron sus acciones en torno a la maternidad voluntaria, la

${ }^{24}$ Ejemplo claro son Eli Bartra y Marta Lamas. La primera tiene un artículo en el que hay un dejo de tristeza al observar que en México las posturas posmodernas del posfeminismo han desmantelado la lucha necesaria contra el patriarcado y, en un país machista, han impedido que las mujeres sean verdaderamente libres. Lamas advierte que la lucha por la soberanía de la mujer sigue en pie, sobre todo en el campo del aborto; pero esta visión le impide admitir otras posturas, como el feminismo teológico (en una entrevista advierte lo insólito que puede ser la sola idea de hablar de un feminismo en alianza con una postura patriarcal que ha mantenido a la mujer subyugada por años). Véase Eli Bartra, "Tres décadas de neofeminismo en México", en Bartra, Fernández Poncela y Lau, op. cit; ; Yearim Ortiz San Juan, "Entrevista a Marta Lamas", Ciudad de México, 20 de enero de 2012. lucha contra la violencia sexual, y la libre opción sexual. ${ }^{25}$ Para la segunda mitad de la década de 1970, la violencia sexual ya era vista como un problema público que se debía enfrentar. Al politizar lo privado, el sexo se descubrió en el espacio público como un instrumento de poder de la sociedad falocrática. Para ellas, todo convergía para asegurar la supremacía viril y la subordinación de las mujeres. ${ }^{26}$

Según publicaciones de la revista $F E M,{ }^{27}$ el poder de los hombres estaba en la punta del falo: "LA VIOLACION NO ES UNA CAUSALIDAD [sic]: es la expresión de la violencia permanente ejercida contra las mujeres en una

${ }^{25}$ Resulta de suma importancia que haya discordancias en las reflexiones actuales de las feministas sobre el movimiento. Por la capacidad crítica con que Tarrés elabora sus textos, sigo sus conclusiones. Sin embargo, tenemos investigaciones de gran relevancia como las de la historiadora Gabriela Cano, en las que advierte que las tres demandas que aglutinaron al movimiento fueron: la despenalización del aborto, la denuncia de la violación como un delito grave que debe ser castigado con rigor y la lucha para evitar violencia doméstica contra las mujeres y para proteger a las víctimas. Gabriela Cano, "Las mujeres en el México del siglo XX. Una cronología mínima", en Lamas, op. cit., pp. 21-75. Lo importante de esto es observar que no hay una narrativa única en la propuesta, lo que permitirá la pluralidad feminista, y cómo para la segunda mitad de la década de 1970 la violencia sexual (incluso en su modalidad de violación) comenzaba a formar parte del discurso público, es decir, empezaba a ser visibilizada.

${ }^{26}$ Se trata de los llamados "contragolpes", que es la violencia sexual ejercida sobre las mujeres como un castigo fálico por "usurpar" un lugar que no les corresponde (el espacio público).

${ }^{27}$ De las primeras publicaciones feministas, si no es que la primera, en donde se abordaban solo temas que incumbían a las nuevas mujeres. 
sociedad patriarcal. Todo hombre es un violador en potencia". ${ }^{28}$ Así, el movimiento comenzó a adoptar ciertos giros y empezó a buscar la despenalización del aborto y que se realizaran cambios sustanciales en la legislación sobre la violación. La sexualidad poco a poco dejaba de ser un recinto cerrado propio de la esfera privada, ahora atañía a toda la sociedad.

En las mismas fechas se fundó el Centro de Apoyo a Mujeres Violadas, que ofrecía orientación jurídica y psicológica a víctimas de violencia sexual y emprendía campañas informativas. La iniciativa provenía de activistas del feminismo. Un gran logro de este y otros esfuerzos semejantes es que transformaron la percepción social sobre la violencia hacia las mujeres. La violación y el hostigamiento sexual empezaron a verse como delitos graves, y no como manifestaciones aceptables de una sexualidad masculina supuestamente incontrolable. ${ }^{29} \mathrm{El}$ paradigma de la violencia y hostigamiento sexual comenzó a cambiar.

Las feministas que iniciaron su activismo en los grupos de autoconciencia establecieron gradualmente su presencia en el espacio público, hasta volverse una referencia en la política mexicana. También fueron apareciendo frentes de mujeres con reivin-

\footnotetext{
${ }^{28}$ Ana Valdemoro, "Crimen contra las mujeres", en FEM, 4 (julio-septiembre 1977), p. 24.

${ }^{29}$ Cano, op. cit.
}

dicaciones particulares: desde las lesbianas, que terminaron por separarse del movimiento feminista, hasta las costureras, cuya situación salió a la luz en el terremoto del 85. En estos nuevos grupos hubo uno muy numeroso que, sin quererlo, dislocó la tambaleante base de las feministas universitarias de clase media: las llamadas "mujeres populares" (trabajadoras de clase baja o mujeres de barrio). Las peticiones de cada colectivo iban desde la libre elección de la sexualidad, hasta el mejoramiento de las condiciones del trabajo femenino o el derecho de la tierra. Sin embargo, todos los frentes tuvieron como una de sus máximas la lucha contra la violencia sexual.

Para la década de 1980, con el proceso de democratización y la consolidación de los grupos de oposición al partido único, muchas feministas se subieron al tren de la democracia para buscar consolidar sus objetivos. Algunas rechazaron esta propuesta por el recelo que seguían teniendo a las instituciones. En esa misma década el feminismo terminó por resquebrajarse. ${ }^{30} \mathrm{Se}$ abrieron paso en el ámbito político los grupos populares que no perseguían necesariamente las tres máximas de las feministas, sino una reivindicación a sus propias necesidades. Algunas feministas lo

\footnotetext{
${ }^{30}$ El feminismo entendido como un ente monolítico. Ahora se abren paso diversos tipos de feminismo.
} 
resintieron como una invasión de su propio espacio.

Así se vio en el "IV Encuentro Feminista Latinoamericano y del Caribe", realizado en Taxco en 1987, donde también se confrontaron los distintos paradigmas políticos. Mujeres de distintos estratos socioculturales asistieron al encuentro, lo que provocó tensiones entre las que se llamaban a sí mismas "feministas" (las universitarias de clase media que se formaron en los grupos de autoconciencia), pues algunas afirmaban que esos encuentros eran solo para las feministas y por lo tanto eran un espacio en donde solo las feministas podían enriquecerse. Aunque las demás mujeres pudieran tener puntos en común con el movimiento, no las veían como partícipes de la ideología de las "revolucionarias sociales". En ese encuentro se creó un discurso que terminó por fragmentar al movimiento: entre las feministas se hablaba de "las otras", que eran aquellas que negaban la identidad feminista como la única, y "nosotras" y "ellas", antagonismo para referirse a sí mismas como las radicales que no querían formar lazos con otros movimientos ni con el Estado, y las feministas de lo posible que entendían que solo en pactos con otros era posible la lucha. ${ }^{31}$

${ }^{31}$ Aquí un fragmento de la entrevista realizada a Marta Lamas, quien fue parte del movimiento feminista: "El primer encuentro feminista que fue en Bogotá, Colombia, en 1981, fue un encuentro donde llegamos 200 mujeres que todas nos asumía-
Sin embargo, a pesar de los desacuerdos entre las feministas y los otros movimientos de mujeres, la lucha contra la violencia sexual siguió de manera firme. Así, en 1982, se refor-

mos como feministas ¿no? Y éramos básicamente universitarias de clase media (por ahí alguna profesora y eso, pero no habían ido ni grupos de campesinas ni grupos de obreras, éramos como muy claramente identificadas como feministas). El siguiente encuentro fue en Perú, y el siguiente fue en Brasil. $Y$ cuando es el encuentro en México, que ya es para 1987, ya había habido un proceso en México en donde muchas feministas que tenían su trabajo político entre campesinas, entre obreras, entre otro tipo de mujeres, mujeres de colonias populares y demás, quisieron llevar a esas mujeres al encuentro; que eran mujeres que no se decían a sí misma feministas, que les podían importar algunos temas de la mujer pero que eran, digamos un grupo muy distinto al que se venía reuniendo antes. Entonces, algunas de las feministas - muchas de las que estaban en el mismo grupo conmigo-y mis amigas decían: 'oigan este es un encuentro entre feministas, que no vengan mujeres que no se sienten feministas por mucho que sus líderes vean la importancia del feminismo y por mucho que quieran que estas se vuelvan feministas'. Entonces sí hay ahí toda una discusión y al final se plantea... que es muy difícil decir quién es feminista y quién no es feminista, que si quieren llegar al encuentro que lleguen. Entonces, al encuentro llegan mujeres, algunas que venían de todos esos procesos en Centroamérica, de la guerrilla guatemalteca y demás que nunca se habían vivido como feministas, pero que a lo mejor estaban descubriendo el feminismo. Estas mujeres de colonias populares y líderes de mujeres campesinas y demás, y las feministas que ya llevábamos en 1987 quince, dieciséis, diecisiete años de estar en los grupitos feministas urbanos. Entonces, sí hay diferencias, digamos, de perspectiva, diferencias de posición, sobre para qué es un encuentro. Para 'nosotras' un encuentro era encontrarnos con otras feministas para discutir de feminismo, y para algunas era que las feministas se encontraran con las mujeres que estaban en el mundo de la política y que pudieran intercambiar ideas. Eran como cosas distintas". Ortiz San Juan, "Entrevista a Marta Lamas", op. cit. 
mó el artículo 264 del Código Penal del Distrito Federal para aumentar la pena, de cuatro a seis años de cárcel, al delito de violación. En 1989 se establecieron las primeras agencias especializadas en delitos sexuales de la Procuraduría de Justicia del Distrito Federal en las delegaciones Miguel Hidalgo, Coyoacán y Venustiano Carranza. A finales de la década de 1980, la violación y la violencia sexual ya eran un problema que atañía no solo a unas cuantas mujeres, sino a la sociedad mexicana. El viejo paradigma había quedado desplazado.

Para la década de 1990, el discurso feminista ya formaba parte del espacio institucional. Incluso se profesionalizó y se volvió parte del discurso académico. Ya no era parte solo de pequeños grupos sociales, los partidos políticos y las instituciones gubernamentales lo habían adoptado. Esto se debió, en gran medida, a la legitimidad de la "Plataforma de Acción" aprobada en Beijing en 1995. ${ }^{32}$ Para asombro de las femi-

${ }^{32}$ En 1995 se llevó a cabo la "IV Conferencia mundial de la mujer en la ciudad de Pekín", que fue un punto clave para los derechos de las mujeres. Ahí se reanudó el trabajo que los movimientos de mujeres habían estado realizando hasta ese entonces, y se volvió a poner el acento en la desigualdad como factor que impedía el pleno desarrollo político, social y económico de los países. La reunión forma parte de una serie de conferencias, la primera realizada en 1975 en México, la segunda en 1980 en Copenhague, y la tercera en 1985 en Nairobi; sin embargo, ninguna alcanzó la relevancia de la cuarta. En Beijing la participación no solo se limitó a los representantes oficiales de cada país (independien- nistas, fue la participación de numerosas mujeres de todas las posiciones ideológicas lo que le dio legitimidad a varias de sus propuestas. La agenda de género pasó a formar parte del sistema político y comenzó a ser difundida o gestionada por sectores sociales inesperados.

Con todo, lo que abrió una acción pluralista y de avance fue el problema de los delitos sexuales y las alianzas a que dio lugar. El progreso en las demandas se había visto frenado por el rechazo de algunas feministas a que el movimiento colaborara con el gobierno (como, por ejemplo, a trabajar con la Procuraduría de Justicia del Distrito Federal para abrir centros especializados en atención a mujeres violadas); sin embargo, se logró avanzar el proyecto, al grado de que, como ya se mencionó, se abrieron Agencias Especializadas en Delitos Sexuales. Este golpe al machismo replanteó la posibilidad de colaborar abiertamente con el Estado. El canal ya había sido abierto, y fue el mismo gobierno el que propuso una discusión sobre la violencia sexual. Varios grupos de feministas, junto con algunas funcionarias públicas, lanzaron la iniciativa de lucha por reformas a la ley de delitos sexuales. Así, en 1990, las

temente de si eran o no feministas), sino que también estuvo abierta a diversos grupos de mujeres de todo el mundo, entre los que por supuesto estuvieron presentes las feministas, las lesbianas y las católicas, quienes fueron un elemento esencial para abrir el debate en torno al concepto de género. 
feministas finalmente lograron reformar el Código Penal del Distrito Federal en materia de delitos sexuales. La reforma aumentó la pena al delito de violación y tipificó los delitos de hostigamiento sexual, abuso sexual, estupro y violación. Este trabajo ha sido considerado como una gran victoria, pues se inauguró la pluralidad en la acción feminista al deslindar las posiciones partidarias de los intereses de género.

Así, la década de 1990 fue un tiempo de apertura de espacios para el diálogo público y para el establecimiento de alianzas entre mujeres con posiciones partidarias y políticas diferentes.

\section{Conclusiones}

Esta brevísima historia del feminismo de la segunda ola en México, deja ver que el siglo de las mujeres fue el siglo XX. Queda mucho por decir, sobre todo en relación con el feminismo mexicano y el plano internacional. Si bien el espacio mexicano tuvo sus particularidades - el contexto social y político de las décadas de 1960 y 1970 - el movimiento se inserta más allá de las fronteras del país.

Actualmente, presenciamos en todo el mundo debates sobre la cuestión de hasta dónde ha de politizarse lo personal. Ha sido necesario volver a plantear qué es lo personal y qué es lo político, poniendo el acento en las relaciones de cortejo entre los sexos. Vemos, para asombro de las feministas de la década de 1970, ${ }^{33}$ que el concepto de violencia sexual se ha estirado hasta abarcar el erotismo y el entramado de las relaciones afectivas, de forma tal que incluso se ha querido regular todo signo de acercamiento entre los individuos al momento de entablar relaciones sentimentales. Al politizar lo personal, las feministas permitieron que el amor (como relación afectiva entre los sexos) se comenzara a entender como un dispositivo cultural levantado sobre la desigualdad estructural entre los sexos, lo que ha puesto de manifiesto que incluso en los ritos de ligue aparezca la violencia contra las mujeres.

Queda mucho por debatir. Podríamos estar o no de acuerdo con las lecturas que sobre la violencia sexual han realizado las feministas, pero lo que no podemos poner en duda es la importancia que el movimiento ha tenido para desnaturalizar la violencia. No se trata de desmantelar toda relación entre los sexos, sino de relaborar las identidades sexuales para poder entablar relaciones más sanas.

${ }^{33} \mathrm{Al}$ respecto, véanse las discusiones de la feminista Marta Lamas con las jóvenes generaciones sobre la campaña Me Too. 
Se prohíbe su reproducción total o parcial por cualquier medio, incluido electrónico, sin permiso previo y por escrito de los editores. 